
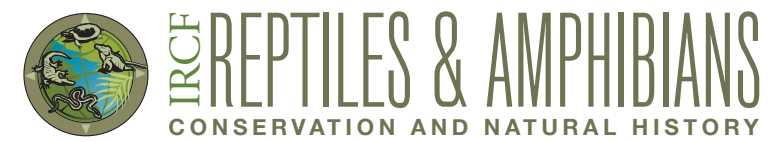

I N T R O D U C E D S P E C I E S

\title{
Madagascar Giant Day Gecko \\ (Phelsuma grandis) Established in Homestead, Miami-Dade County, Florida, USA
}

Thomas W. Fieldsend ${ }^{1}$ and Kenneth L. Krysko ${ }^{2}$

${ }^{1}$ Department of Biological Sciences, Florida International University, Miami, Florida 33199, USA (thomasfieldsend@hushmail.com)

${ }^{2}$ Florida Museum of Natural History, Division of Herpetology, University of Florida, Gainesville, Florida 32611, USA (langaha01@yahoo.com)

$\mathrm{T}$ he Madagascar Giant Day Gecko (Phelsuma grandis) is native to northern Madagascar, but is an established nonnative species in Mauritius, Reunion (Dubos 2013), Florida (Krysko et al. 2019), and Hawaii (Kraus 2002). In Florida, $P$. grandis was first introduced via the pet trade on Little
Torch Key in 1997 (Krysko et al. 2019) and by 2002 was also established on Grassy Key, Big Pine Key, and Plantation Key (Krysko et al. 2003). Breeding populations were known only from Monroe County in the Florida Keys until 2017, when a population was reported from the Glenvar Heights area of

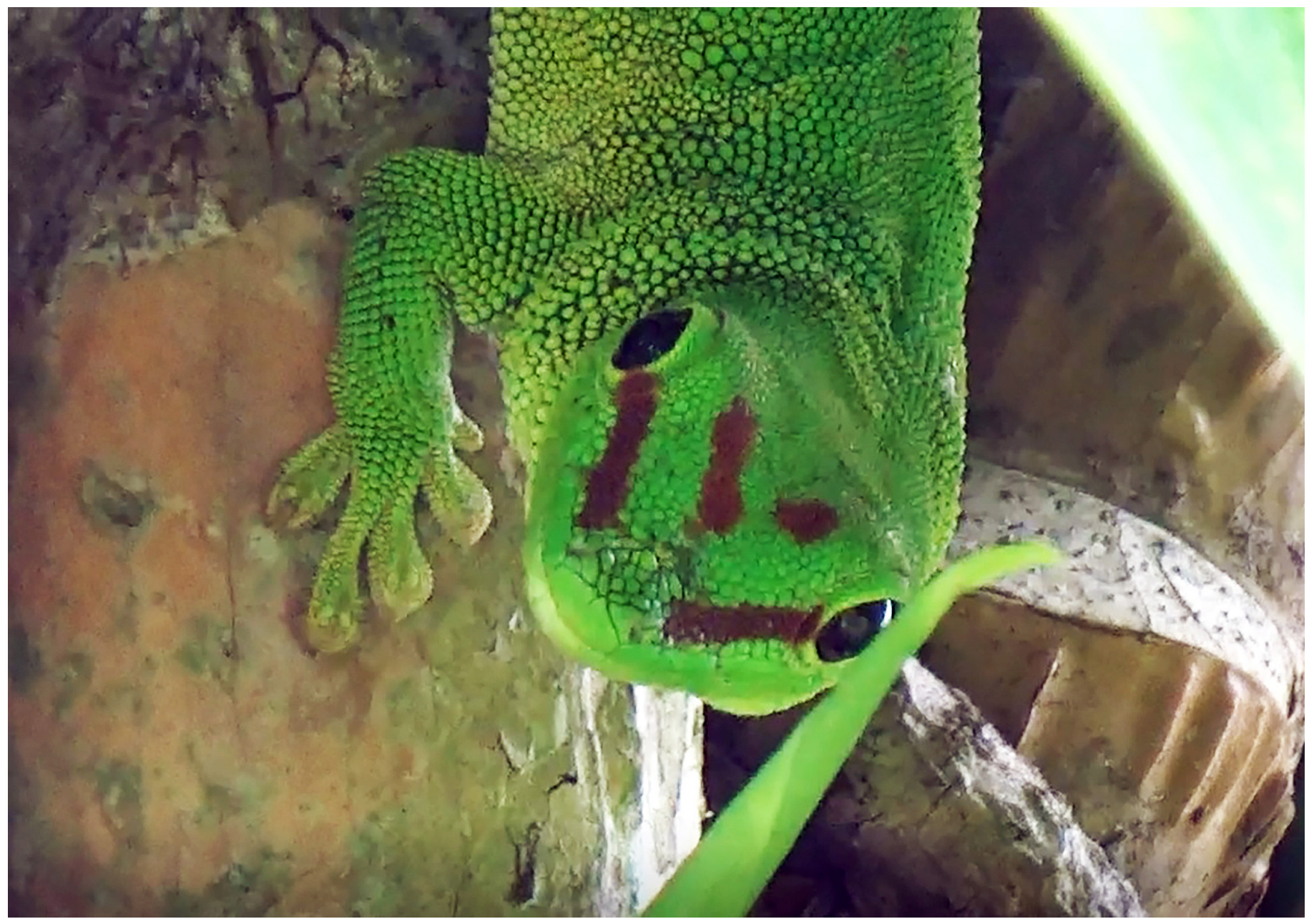

Fig. 1. Adult nonnative Madagascar Giant Day Gecko (Phelsuma grandis) in Homestead, Miami-Dade County, Florida, USA on 22 April 2019. Photograph by Thomas Fieldsend. 
Miami, Miami-Dade County (Thawley and Stroud 2017). Herein, we report a second breeding population of $P$. grandis from Miami-Dade County, approximately 38 km (23.6 mi) southwest of the Glenvar Heights population.

On 22 April 2019 at 1035 h, four Phelsuma grandis were observed on private property near the corner of SW 348 Street and SW 212 Avenue in Homestead $\left(25.44389^{\circ} \mathrm{N}\right.$, $\left.80.53387^{\circ} \mathrm{W}\right)$. One adult and two subadults were observed on a single coconut palm (Cocos nucifera), and a second adult was observed on a nearby Philodendron (Philodendron sp.). Photographic vouchers were deposited in the Florida Museum of Natural History (UF-Herpetology 185566 185569). Coleman M. Sheehy III confirmed the identity of the species from photographs.

This population was introduced via the pet trade during the 2000s. The property owner stated that the population survived the prolonged cold weather of 2010, during which lows of $-1.1^{\circ} \mathrm{C}\left(30^{\circ} \mathrm{F}\right)$ and $-0.55^{\circ} \mathrm{C}\left(31^{\circ} \mathrm{F}\right)$ were recorded on consecutive days (11-12 January; National Oceanic and Atmospheric Administration records). The apparent survival of this population at temperatures below freezing suggests that $P$. grandis might be able to colonize more-northerly areas of Florida than might have been assumed a priori, given the species' wholly tropical native range (Raxworthy et al. 2007).

\section{Acknowledgments}

We thank the property owner for allowing us to survey his property and for information on the introduction history of Phelsuma grandis.

\section{Literature Cited}

Dubos, N. 2013. New locality record for Phelsuma grandis (Sauria: Gekkonidae) in Reunion, in sympatry with the critically endangered Phelsuma inexpecta. Herpetology Notes 6: 309-311.

Kraus, F. 2002. New records of alien reptiles in Hawaii. Bishop Museum Occasional Papers 69: 48-52.

Krysko, K.L., A.N. Hooper, and C.M. Sheehy III. 2003. The Madagascar Giant Day Gecko Phelsuma madagascariensis grandis Gray 1870 (Sauria: Gekkonidae): A new established species in Florida. Florida Scientist 66:222-225.

Krysko, K.L., K.M. Enge, and P.E. Moler. 2019. Amphibians and Reptiles of Florida. University Press of Florida, Gainesville, Florida.

Raxworthy, C.J., C.M. Ingram, N. Rabibisoa, and R.G. Pearson. 2007. Applications of ecological niche modeling for species delimitation: A review and empirical evaluation using day geckos (Phelsuma) from Madagascar. Systematic Biology 56: 907-923.

Thawley, C.J. and J.T. Stroud. 2017. Phelsuma grandis (Madagascan Day Gecko). Herpetological Review 48: 812-812. 